\title{
Revisión
}

\section{Ingeniería de la célula madre}

Servicio de Inmunología y Reumatología Pediátrica Hospital Nacional de Niños "Dr. Carlos Sáenz Herrera" Caja Costarricense de Seguro Social

\begin{abstract}
Abreviaturas: $\mathrm{CM}$, célula madre; $\mathrm{CMH}$, célula madre hematopoyética; CME, célula madre embrionaria; CMM, célula madre mesenquimatosa; $\mathrm{CMH}-\mathrm{sp}$, célula madre hematopoyética de sangre periférica; $\mathrm{CMH}$-mo, célula madre hematopoyética de médula ósea; $\mathrm{CMH}-\mathrm{cu}$, célula madre hematopoyética de cordón umbilical; SCU, sangre de cordón umbilical; TMO, trasplante de médula ósea; MO, médula ósea; LTR, células con potencial de repoblación de larga duración;
\end{abstract}

\section{Correspondencia:}

Dr. Oscar Porras Madrigal (PhD)

Servicio de Inmunología y Reumatología Pediátrica

Hospital Nacional de Niños

"Dr. Carlos Sáenz Herrera"

Apartado 1654 1000, San José,

Costa Rica.

Email: oporrasm@hnn.sa.cr

ISSN 0001-6002/2005/47/2/69-75 Acta Médica Costarricense, (C2005 Colegio de Médicos y Cirujanos

\begin{abstract}
Oscar Porras
Resumen

La ingeniería de la célula madre (CM) es una tecnología aplicable en la solución de problemas de salud del ser humano relacionados con la reconstrucción de tejidos y la restauración de la función celular normal en enfermedades metabólicas, hematológica, inmunológicas y degenerativas. La investigación en la biología de la $\mathrm{CM}$ ha permitido definirle una identidad y establecer un grupo de células de diferente origen que comparten las características de autorrenovación y plasticidad. Este grupo incluye células embrionarias, mesenquimatosas, hematopoyéticas, umbilicales y residentes en tejidos como las CM neuronales.

La investigación sobre todo con células embrionarias y los procedimientos de clonación reproductiva y trasplante de núcleos han generado un debate ético, político y religioso, en el cual solamente podemos establecer nuestra opinión si conocemos los conceptos básicos de la biología e ingeniería de las células madre.
\end{abstract}

Descriptores: Célula madre, "Stem cell", hematopoyesis, trasplante de células hematopoyéticas, sangre de cordón umbilical, clonación, transferencia de núcleos, clonación terapéutica, clonación reproductiva, plasticidad.

Recibido: 1 de marzo de 2005

Aceptado: 29 de marzo de 2005

\section{Introducción}

La restauración de tejidos en los seres humanos requiere del reclutamiento y proliferación de células capaces de devolverles forma y función. Las células involucradas en la regeneración recuerdan todo el proceso de desarrollo que llevó a la formación original del tejido. El concepto inicial, de que poblaciones de células indiferenciadas, autorrenovables y progenitoras, regeneran solamente el órgano en que residen, ha sido sustituido por el de células multipotentes, que pueden ser aisladas de diferentes tejidos en el ser humano ${ }^{1}$. A este grupo de células se le conoce como Células Madre (CM), se originan de tejido embrionario o de tejidos diferenciados y se caracterizan por su capacidad de autorrenovarse y por su pluripotencialidad o capacidad de diferenciarse en diferentes tipos de progenitores maduros ${ }^{1-4}$.

Una CM debe ser clonogénica: capaz de autorrenovarse ilimitadamente por medio de división simétrica. Debe ser capaz de división asimétrica: dando origen a una célula hija igual a la madre y a otra capaz de originar varios tipos de células diferenciadas de los tres tipos embrionarios (ectodermo, mesodermo y endodermo). Debe originarse de una célula embrionaria o de una $\mathrm{CM}$ adulta $1,2,4,5$.

La pluripotencialidad fue descrita inicialmente en la célula madre embrionaria (CME) cuando se demostró su diferenciación hacia endodermo, ectodermo y mesodermo ${ }^{3,6-8}$. Células procedentes de médula ósea adulta, cordón umbilical y endotelio muestran capacidad de diferenciación y han permitido ampliar el espectro de tipos de CM con potencial de aplicación clínica en el tratamiento de diferentes patologías del ser humano. Las CM se pueden dividir por su origen en embrionarias y somáticas posnatales ${ }^{3}$. 
En este artículo se discuten conceptos básicos sobre la biología de la CM y su aplicación en el tratamiento de enfermedades congénita, malignas, y metabólicas, así como en la regeneración de tejidos. El objetivo de esta revisión, es aportar al conocimiento necesario para que el lector pueda percibir el potencial terapéutico de las tecnologías derivadas de la ingeniería de la CM y participé del debate ético, religioso y político que se ha generado.

\section{Conceptos y procedimientos}

Para la comprensión de la biología e ingeniería de la CM es necesario tener claro los conceptos y procedimientos que se involucran.

Transferencia de núcleos. Se conoce también como clonación nuclear o trasplante nuclear. Es la tecnología que creó a la oveja Dolly en 1997, el primer mamífero clonado. El experimento demostró que el $\mathrm{ADN}$ se conserva durante el desarrollo de organismos multicelulares, que existe la posibilidad de la aplicación de esta tecnología en la regeneración de tejidos y órganos y en la recapitulación celular a partir de células somáticas posnatales y que es posible la creación de CME autólogas ${ }^{3,9}$.

La transferencia de núcleos es un procedimiento en el que el núcleo de una célula somática pos-mitótica (célula adulta) se inyecta en un oocito no fertilizado al que se ha despojado de su núcleo. Se crea un blastocisto (embrión clonado) que puede ser transferido para su desarrollo al útero de una madre adoptiva donde crece una progenie, que es un clon de la célula adulta donadora. El proceso se identifica como clonación reproductiva. También se puede separar la masa de células internas del blastocisto, de la cual se derivan CME indiferenciadas, que se inducen a diferenciación y propagación de las células de un tejido específico, en el proceso conocido como clonación terapéutica o terapia con trasplante nuclear. Las células obtenidas son genéticamente idénticas al donador ${ }^{3,10,11}$.

Un experimento que demuestra la factibilidad de esta tecnología es el tratamiento de ratones con Inmunodeficiencia Combinada Grave (SCID Rag2), con células derivadas de transferencia nuclear y que permiten la corrección genética y fenotípica de la enfermedad ${ }^{12}$.

La clonación reproductiva es aún un proceso ineficiente que produce la perdida de la mayoría de los clones durante la etapa de desarrollo. Para lograr desarrollarse, el clon debe activar genes que regulan el desarrollo embrionario temprano y suprimir genes asociados con diferenciación de la célula donadora original. Debe darse una reprogramación del núcleo donado, que cuando es inadecuada, causa la pérdida del clon. Los errores de reprogramación no afectan la clonación terapéutica ${ }^{3,10,12,13}$.
Terapia con genes. Es un procedimiento en el cual se trata de curar una enfermedad, en la que se ha identificado como causa la mutación de un gen. Tiene como objetivo restaurar, modificar o mejorar la función de una célula a través de la introducción de un gen sano. El gen sano se integra en un vector, usualmente un virus, que infecta las células del paciente. Al activarse el gen sano restituye la función de la célula dañada. Se han diseñado dos formas de introducir el material genético, una in vivo por medio de la cual, un vector transporta el ADN, que se integra en el genoma de la célula blanco y expresa el gen de interés terapéutico. El otro método, ex vivo, transfiere el gen a células en cultivo y luego se trasplantan las células modificadas al tejido blanco ${ }^{14}$.

Una de las aplicaciones de esta metodología en el ser humano, es la corrección del defecto genético en niños con SCID-X1 y en casos de SCID producidos por deficiencia de adenosina diaminasa (ADA) ${ }^{15-18}$.

El entusiasmo inicial por la terapia con genes, ha disminuido como consecuencia de los malos resultados de los estudios clínicos y los efectos adversos provocados por la respuesta inmune contra el vector ${ }^{18}$. Recientemente se reportó la generación de leucemia de células $\mathrm{T}$ en niños tratados por SCID, como consecuencia de la inserción del vector en el locus del gen LOM-2 ${ }^{18-20}$. Este gen codifica un factor de trascripción necesario para la hematopoyesis normal, pero que cuando se expresa en forma aberrante se asocia con leucemia infantil ${ }^{21}$.

Plasticidad. Es la característica que se identifica en una célula que, comprometida con la generación de un tejido específico, se puede diferenciar en células de otros tejidos para los cuales no estaba predeterminada. Esta definición tiene implícito el concepto de la existencia de CM con una línea de maduración no determinada que tienen la capacidad de diferenciarse en tejidos diferentes, dependiendo del patrón a que las induzcan los factores de su microambiente ${ }^{1,3,4,22,23}$.

Transdiferenciación. Cambios de linaje o de diferenciación restringida de la $\mathrm{CM}$, ocurren cuando una $\mathrm{CM}$ adulta cambia su diferenciación esperada a una que produce células adultas diferenciadas de un órgano diferente. Este proceso ha aumentado las expectativas del uso de $\mathrm{CMH}$ en aplicaciones clínicas que van mas allá de la reconstitución hematológica o inmunológica. Transdiferenciación es el proceso que explica como $\mathrm{CM}$ adultas tejido-específicas pueden generar células de otros tejidos ${ }^{3,24}$.

Fusión. Algunos tipos celulares son capaces de fusionarse con células de otro linaje y de adoptar la forma y función de las células con las que se fusionaron. Se ha identificado transdiferenciación que tiene origen en el donador, en la cual células de MO trasplantadas cambian a líneas celulares que incluyen miocitos, hepatocitos y neuronas entre otras. Este fenómeno se explica por fusión celular espontánea, después de la cual, las células adoptan el fenotipo de la célula receptora. Este proceso puede explicar muchos de los reportes de transdiferenciación ${ }^{1,25,26}$. 


\section{Fenotipo de la célula madre}

Las CM deben ser aislables, homogéneas por purificación y bien caracterizadas antes de que se utilicen para realizar experimentos in vivo. Cuando la célula se anida en un tejido, debe desarrollar una función específica demostrable del tejido en el que se aloja ${ }^{2,4}$.

La CM debe ser capaz de división celular asimétrica, que produzca una replica idéntica de la CM y una célula que pueda desarrollar una función más especializada. La producción de células que se diferencian provoca la perdida de la población fundadora ${ }^{1,4}$.

Las CM pueden ser aisladas en diferentes tejidos identificando características físicas e inmunofenotípicas. Utilizando marcadores de superficie en las CM, con citometría de flujo y detectando la emisión de fluorescencia con tinciones específicas, se pueden identificar diferentes poblaciones de $\mathrm{CM}^{4}$.

Las célula madre hematopoyéticas $(\mathrm{CMH})$ humanas se caracterizan por su alta expresión de CD34, intermedia de c-kit y Thy-1 y baja o ninguna de CD38, HLA-DR, CD45RA y CD71. También expresan niveles altos de glicoproteína $\mathrm{P}$ (P-gp). Otros marcadores identifican células más primitivas como las CD34- precursoras de la $\mathrm{CMH} \mathrm{CD} 34+$ y los grupos celulares que expresan KDR. Entre 0,1 a $0,5 \%$ de las CMH CD34+ en la MO, CU y SP de los seres humanos expresan el receptor 2 del factor de crecimiento del endotelio vascular (VEGFR2 o KDR), lo cual permite especular que los fenotipos CD34-KDR+ y CD34+KDR+ corresponden al hemangioblasto postnatal y prenatal, la célula progenitora de los linajes sanguíneo y endotelial, con lo cual se establece una conexión entre angiogenesis y hematopoyesis ${ }^{2,27-32}$.

Una población celular que corresponde al 0,05\% de la población celular de la MO y que emite fluorescencia con la tinción Hoechst 33342, se ha denominado como población SP ("side population") y tiene un fenotipo similar a la CM adulta de la $\mathrm{MO}$, pero con gran potencial de diferenciación e integración en otros órganos ${ }^{2}$. Un $20 \%$ de la población de células SP, expresan Endoglobina (receptor del factor de transformación del crecimiento ß) e intervienen en el desarrollo de vasos sanguíneos y del corazón del embrión ${ }^{2,27,28}$. La población de células SP en el pulmón embrionario está compuesta por progenitores hematológicos y no hematológicos y son parte de la formación de la vasculatura pulmonar ${ }^{33}$.

\section{Tipos de células madre}

Embrionarias. Son células que se pueden derivar de los blastocistos durante la gastrulación. Separadas del blastocisto se pueden mantener indiferenciadas, formando cuerpos embriónicos de los que se pueden desarrollar líneas celulares embrionarias tempranas, con capacidad ilimitada de autorrenovación y capacidad de diferenciación. Tienen el potencial de originar todas las células somáticas y germinales de un individuo completo y son los progenitores de las tres capas embrionarias germinales: ectodermo, endodermo y mesodermo ${ }^{3,34-36}$.

A pesar de su potencial, es necesaria la identificación de muchos mecanismos relacionados con la regulación de su crecimiento y diferenciación, el desarrollo de teratomas y la discusión amplia de los aspectos éticos sobre su uso, antes de que se desarrolle una aplicación clínica ${ }^{1,4,5}$.

Dentro de la controversia por el uso de material obtenido de fetos, se debe distinguir entre CME y tejidos fetales. Las CME se derivan de la capa interior de los embriones y los tejidos fetales se obtienen de productos de abortos. El tejido fetal ha tenido un uso en terapia e investigación, menos restringido ${ }^{37}$.

La CME es la que más controversia ética, religiosa y política ha provocado. En su contra se argumenta que su uso requiere la destrucción de embriones humanos y que la investigación en el tema abre las puertas para procesos más controversiales como clonación, criaderos de embriones y uso de fetos como fuente de tejidos ${ }^{36,38}$.

El aceptar o no que la adquisición del alma ocurre al momento de la concepción, y por ende todo embrión es un ser humano, lleva a considerar que la destrucción de embriones humanos en proyectos de investigación con $\mathrm{CME}$ es equivalente a matar seres humanos ${ }^{39,40}$.

El descubrimiento de $\mathrm{CM}$ en la médula ósea y en el cordón umbilical, plantea la posibilidad de obtener células pluripotenciales, sin tener que recurrir al uso de embriones ${ }^{41}$. También se puede evitar el uso de embriones por medio de la transferencia de núcleos de células somáticas ${ }^{41}$. Otra opción al uso de embriones, es utilizar óvulos no fertilizados a los cuales se induce a partenogénesis ${ }^{40}$.

Una línea de investigación que aportaría una opción a en la discusión sobre el uso de embriones, en la cual los argumentos principales son: "Los embriones humanos no deben ser destruidos en el proceso de crear células madre" y que "investigación que produce un gran beneficio, no se justifica si se debe pagar como precio el violar derechos humanos fundamentales", es la que trata de identificar cuales embriones han perdido la capacidad, en el estadío de 4 a 8 células, de mantener una división celular continua e integrada, crecer y diferenciarse. Con la identificación de esta condición, se puede determinar la muerte funcional del embrión, aunque no así de cada una de sus células y es posible establecer una posición ética semejante a la de la declaración de muerte cerebral que indica el fin de la vida por consenso y que permite el uso de órganos funcionales para trasplantes ${ }^{38}$. 
Alrededor de $60 \%$ de los embriones utilizados para fertilización in vitro, no cumplen con los criterios de viabilidad y son rechazados para transferencia uterina. No viable significa incapacidad para desarrollarse hasta el nacimiento. Este concepto defiere del de embrión muerto, pero sin embargo indica la posibilidad de tener criterios de consenso, que a nivel embrionario, definan embriones que se pueden declarar muertos. Estos embriones muertos mantienen grupos de células viables para obtener CME, utilizables en investigación y terapia ${ }^{8,38}$.

Somáticas pos-natales. Son una fuente de células pluripotenciales, se conoce su existencia como células madre específicas de algunos tejidos, con la función de ser progenitores de las células especializadas en cada tejido. Representan un grupo heterogéneo de células que incluye las de las criptas del intestino, las ovales hepáticas y las hematopoyéticas, dando origen al concepto de células madre adultas específicas de los tejidos. Estos tipos de células se consideraban con diferenciación irreversible, sin embargo se ha demostrado que pueden generar otras líneas de diferenciación en tejidos en los que no residen ${ }^{1,3}$.

Es el ejemplo de las $\mathrm{CMH}$ que pueden diferenciarse en neuronas, hepatocitos, miocardio y músculo esquelético, a pesar de que residen en la médula ósea.

Hematopoyéticas: se les define por sus características funcionales de regenerar y mantener todas las células mieloides y linfoides maduras que encontramos en sangre periférica, médula ósea, bazo y timo ${ }^{4}$. También son capaces de transdiferenciarse en células de tejidos no hematopoyéticos como hígado, páncreas, corazón, cerebro, y riñón. Las $\mathrm{CMH}$ son pluripotentes, con alto potencial de proliferación y autorrenovables ${ }^{27}$. Se ha demostrado la presencia de hepatocitos, cardiomiocitos y neuronas con cromosoma $\mathrm{Y}$ en mujeres que recibieron trasplantes de médula ósea de donadores masculinos $13,4,27,42,43$.

La CMH tiene un ciclo de renovación de alrededor de 30 días, son inducidas a hematopoyésis y experimentan una serie de divisiones para la maduración donde coexisten progenitores con células que aumentan su diferenciación y restringen su proliferación hasta alcanzar los linajes mieloide o linfoide. Las células maduras tiene una vida que varia en el ser humano de 1 día en neutrófilos a 120 días en los eritrocitos. Mantener números adecuados de células maduras requiere de la activación secuencial de clonas de CM sucesivas. Este proceso esta regulado por glicoproteínas que actúan como factores de crecimiento o como inhibidores de proliferación y por citoquinas ${ }^{27,28}$.

En la médula ósea, menos del $0,1 \%$ de las células hematopoyéticas son CM pluripotenciales capaces de proliferación a tiempo prolongado y autorrenovación.

El procedimiento que mejor las define es la capacidad de mantener la regeneración completa del sistema linfohe- matopoyético por más de seis meses después de TMO, que identifica un grupo de células de cantidad variable con potencial de repoblación por largo tiempo (LTR) ${ }^{27,28,30}$.

En adultos la mayoría de las $\mathrm{CMH}$ se encuentran en la $\mathrm{MO}$, donde se asocian con células madre mesenquimatosas (CMM) y constituyen el microambiente hematopoyético, en donde producen los factores de estimulación e inhibición del crecimiento que regulan su desarrollo. El tráfico de algunas de las células LTR a través de la circulación explica su amplia distribución en todo el organismo en tejidos que no son hematopoyéticos como el músculo esquelético, riñones, corazón, pulmón, hígado, cerebro e intestino delgado. En el ser humano las $\mathrm{CMH}$ pueden ser movilizadas a sangre periférica con el factor de crecimiento de colonias de granulocitos (G-CSF), permitiendo la selección de este grupo de células para trasplante utilizando protocolos de trasplante con células de sangre periférica.

Durante la vida fetal las $\mathrm{CMH}$ obtenidas del hígado tienen tasas de proliferación mayores que las $\mathrm{CMH}$ de la MO. Sin embargo la CMH-f tienen defectos para la nidación en la MO por formas de integrinas de baja afinidad que no permiten una buena adherencia a las células del estroma ${ }^{27,28}$.

Cordón umbilical: son una fuente de $\mathrm{CMH}$ trasplantables, primitivas en su origen ontogénico, disponibles sin riesgo de obtención para el donador y crioconservables a partir del nacimiento ${ }^{28,31,44-46}$.

Por la inmadurez del sistema inmune del recién nacido, los linfocitos presentes en la sangre del cordón umbilical (SCU) son más tolerantes de los antígenos leucocitarios humanos (HLA) y permiten su uso en casos en que hay más discrepancias entre donador y receptor, provocando menos enfermedad injerto versus huésped (Ellas) en el receptor cuando se hacen alotrasplantes. Esto permite conseguir un donador con más facilidad, sin embargo cuando se les compara con $\mathrm{CMH}$ obtenidas de MO o SP las de CU tienen un tiempo de implantación mayor y las dosis de células disponibles para el trasplante son menores ${ }^{44,45}$.

Sin embargo su capacidad de expansión puede ser utilizada en la actualidad para inducir proliferación in vitro y mejor la dosis de células disponible para el trasplante ${ }^{47,48}$.

Mesenquimatosas: representan un segundo grupo de células progenitoras que residen en la $\mathrm{MO}$, se les consideraba como las células del estroma o el sustrato celular de soporte para las CMH. Recientemente se ha demostrado su capacidad de convertirse varios linajes de células mesenquimatosas como adipocitos, condrocitos y osteoblastos. Es una célula con una aplicación potencial en la regeneración del tejido conectivo. Se ha identificado su presencia en los componentes del cordón umbilical ${ }^{49}$.

Adultas progenitoras multipotentes: se han identificado como una población de la MO, con capacidad semejante a 
las CME. Se han aislado también de músculo y del cerebro. Son capaces de adoptar fenotipos funcionales de ectodermo (neuronas), endodermo (hepatocitos) y linajes mesenquimatosos y hematopoyéticos ${ }^{4}$.

\section{Aplicaciones clínicas}

Trasplante de células hematopoyéticas. El trasplante de $\mathrm{CMH}$ ha sido la aplicación clínica más conocida de las CM. Las diferentes variantes del procedimiento permiten el uso de células del receptor (autólogo) o de un donador (alogénico). El trasplante alogénico puede realizarse con células obtenidas de un donador familiar idéntico o de uno haploidéntico, en el que se ha depletado el paquete celular de Linfocitos T. También es posible utilizar un donador idéntico no familiar, identificándolo en un registro internacional.

Las células para el trasplante se pueden obtener por aspiración de médula ósea, de sangre periférica después de movilizarlas con factores de crecimiento hematopoyético o bien de cordón umbilical ${ }^{50}$. Cada tipo de trasplante se adapta a la patología que se desea tratar y a la disponibilidad del donador. Los resultados de los diferentes tipos de procedimientos permiten compararlos utilizando parámetros como sobrevida, morbilidad, enfermedad injerto vs huésped, reconstitución del número de neutrófilos y el tiempo transcurrido hasta la implantación ${ }^{51-55}$.

El trasplante usando CMH-cu ha mejorado las posibilidades de tratamiento de muchos pacientes, al dar la opción de utilizar un injerto con menos restricciones de compatibilidad con el receptor. Sin embargo el periodo de tiempo de implantación es mayor y la recuperación hematológica más tardía.

Las células hematopoyéticas progenitoras de cordón umbilical, son una alternativa para la médula ósea en trasplantes. El primer trasplante con sangre de cordón umbilical se realizó en $1988{ }^{47}$. El resultado del trasplante usando CU o MO son similares y no hay diferencias de toxicidad. A favor de las CMCU está la mayor facilidad de identificar un donador, la disponibilidad inmediata de las células criopreservadas, la ausencia de riesgos para el donador y una mejor tolerancia inmunológica que permite menos restricciones por incompatibilidad HLA ${ }^{47,51,52,56}$.

Sin embargo al comparar el uso de CMH-cu con CMHmo se evidencia que la recuperación del neutrófilos y plaquetas es más tardía, hay mayor riesgo de fallas de implantación y mayor mortalidad asociada con el trasplante en los primeros 100 días ${ }^{52,57}$.
La principal restricción al uso de CMCU es las limitaciones en la dosis de $\mathrm{CM}$ disponibles para trasplante, en especial en adultos, debido a que este es un factor asociado con implantación y sobrevida. Sin embargo la investigación en los métodos de expansión ex vivo de las CMCU puede resolver el problema de dosis celular ${ }^{48,56-58}$.

En una comunidad se pueden dar dos tipos de opciones para obtener CMCU: una en la cual, en forma privada, se crioconserva células al nacimiento para el uso exclusivo del donador o de algún miembro de su familia, y otra opción en la que las células se conservan en forma anónima y se utilizan como donación para el receptor que las requiera en el manejo de una enfermedad congénita, hematológica, inmunológica o maligna ${ }^{55,59}$. Los bancos de CMH-cu han demostrado en New York y Londres, que son una opción de trasplante con resultados excelentes ${ }^{60,61}$.

Reconstitución de tejidos. Una de las aplicaciones clínicas en desarrollo activo de la ingeniería de la CM, es la posibilidad de utilizar su plasticidad para reconstituir tejidos dañados o con procesos degenerativos por diversas enfermedades.

Células de la médula ósea pueden anidar y diferenciarse en miocitos ${ }^{62}$. En el modelo de ratón de la Distrofia muscular de Duchenne, las células diferenciadas producen factores de trascripción, miogenina y distrofina, demostrando que la $\mathrm{CMH}$-mo son capaces de migrar, anidar, diferenciarse hacia el linaje miogénico y fusionarse con las miofibrillas en respuesta a un daño químico o genético, indicando la posibilidad de reparación del tejido dañado ${ }^{63}$.

En el sistema nervioso central, CMH-mo, anidan y expresan proteínas neuronales ${ }^{64}$.

Procesos semejantes de diferenciación se han reportado, hacia células hepáticas ${ }^{65,66}$, neuronas ${ }^{4}$, vasos sanguíneos, músculo esquelético, riñón, pulmón, piel y hueso ${ }^{4,22,50}$. Las células CME se diferencian en estructuras que secretan insulina y semejan islotes del páncreas ${ }^{67}$.

El comportamiento de las CMH-mo en el sistema nervioso central y en el corazón ha permitido plantear la posibilidad de trasplantar estas células en estos dos tejidos, para contribuir a la reparación de las lesiones, con la generación de tejido nuevo ${ }^{52}$.

El potencial de diferenciarse en cardiomiocitos se ha demostrado en CME, CMMO, CMM y en una población de células cardiacas progenitoras residentes en el tejido cardiaco ${ }^{68-72}$.

La investigación en el campo del trasplante de mioblastos, ha demostrado que esta tecnología tiene el potencial de ser un componente importante en el manejo de las lesiones isquémicas y en el tratamiento de la falla cardiaca con mejoría de la contractilidad cardiaca ${ }^{73-75}$. 


\section{Abstract}

Stem cell engineering is a technology applicable to the solution of health problems of human beings, regarding particularly tissue reconstruction and the reestablishment of normal cell function in metabolic, hematological, immunological and degenerative disorders.

Research of stem cell biology has led to the recognition of its own identity and to establish a group of cells of different origin that share characteristics of self renovation and plasticity. This group encompasses embryonal, mesenchymal, hematopoietical, umbilical and other cells that reside in tissues such as neuronal stem cells.

Investigation of embryonal stem cells and the procedures of reproductive clonation and nuclear transplant have triggered an ethic debate, of political and religious aspects. We can only voice our opinion if we know the basic principles of the biology and engineering of stem cells.

\section{Referencias}

Rosenthal N. Prometheus's vulture and the stem-cell promise. N Engl J Med 2003; 349:267-274.

Garrido Colino C. Estado actual de la investigación con células madre. An Pediatr (Barc) 2003; 59:552-558.

Sylvester KG, Longaker MT. Stem cells: review and update. Arch Surg 2004; 139:93-99.

4. Blau HM, Brazelton TR, Weimann JM. The evolving concept of a stem cell: entity or function? Cell 2001; 105:829-841.

van der Kooy D, Weiss S. Why stem cells? Science 2000; 287:1439-

Evans MJ, Kaufman MH. Establishment in culture of pluripotential stem from mouse embryos. Nature 1981; 292:154-156.

Bradley A, Evans M, Kaufman MH, Robertson E. Formation of germ-like chimaeras from embryo-derived teratocarcinoma cell lines. Nature 1984; 309:255-256.

8. Thomson JA, Itskovitz-Eldor J, Shapiro SS, Waknitz MA, Swiergiel JJ, Marshall VS, et al. Embryonic stem cell lines derived from human blastocysts. Science 1998; 282:1145-1147.

9. Wilmut I, Schnieke AE, McWhir J, Kind AJ, Campbell KH. Viable offspring derived from fetal and adult mammalian cells. Nature 1997; 385:810-813.

10. Hochedlinger K, Jaenisch R. Nuclear transplantation, embryonic stem cells, and the potential for cell therapy. N Engl J Med 2003; 349:275-286.

11. Lisker R. Ethical and legal issues in therapeutic cloning and the study of stem cells. Arch Med Res 2003; 34:607-611.

12. Rideout WMIII, Hochedlinger K, Kyba M Daley GO Jaenisch. Correction of a genetic defect by nuclear transplantation and combined cell and gene therapy. Cell 2002; 109:17-27.

13. Gurdon JB, Byrne JA, Simonsson S. Nuclear reprogramming and stem cell creation. Proc Natl Acad Sci USA 2003; 100:11819-11822.

14. Selkirk SM. Gene therapy in clinical medicine. Postgrad Med J 2004; 80:560-570.
Cavazzana-Calvo M, Hacein-Bey-Abina S, de Saint BG, Gross F, Yvon E, Nusbaum P, et al. Gene therapy of human severe combined immunodeficiency (SCID)-X1 disease. Science 2000; 288:669-672.

16. Hacein-Bey-Abina S, Le Deist F, Carlier F, Bouneaud C, Hue C, de Villartay JP, et al. Sustained correction of X-linked severe combined immunodeficiency by ex vivo gene therapy. N Engl J Med 2002; 346: 1185-1193.

17. Aiuti A, Slavin S, Aker M, Ficara F, Deola S, Mortellaro A, et al. Correction of ADA-SCID by stem cell gene therapy combined with nonmyeloablative conditioning. Science 2002; 296:2410-2413

18. Nathwani AC, Davidoff AM, Linch DC. A review of gene therapy for haematological disorders. Br. J Haematol 2005; 128:3-17.

19. Hacein-Bey-Abina S, von Kalle C, Schmidt M, McCormack MP, Wulffraat N, Leboulch P, et al. LMO2-associated clonal T cell proliferation in two patients after gene therapy for SCID-X1. Science 2003; 302:415-419.

20. Hacein-Bey-Abina S, von Kalle C, Schmidt M, Le Deist F, Wulffraat $\mathrm{N}$, McIntyre E, et al. A serious adverse event after successful gene therapy for X-linked severe combined immunodeficiency. N Engl J Med 2003; 348: 255-256.

21. McCormack MP, Rabbitts TH. Activation of the T-cell oncogene LMO2 after gene therapy for X-linked severe combined immunodeficiency. N Engl J Med 2004; 350:913-922.

22. Horwitz EM. Stem cell plasticity: the growing potential of cellular therapy. Arch Med Res 2003; 34:600-606.

23. Krause DS, Theise ND, Collector MI, Henegariu O, Hwang S, Gardner R, et al. Multi-organ, multi-lineage engraftment by a single bone marrow-derived stem cell. Cell 2001; 105:369-377.

24. Wurmser AE, Gage FH. Stem cells: cell fusion causes confusion. Nature 2002; 416:485-487.

25. Terada N, Hamazaki T, Oka M, Hoki M, Mastalerz DM, Nakano Y, et al. Bone marrow cells adopt the phenotype of other cells by spontaneous cell fusion. Nature 2002; 416:542-545.

26. Ying QIL, Nichols J, Evans EP, Smith AG. Changing potency by spontaneous fusion. Nature 2002; 416:545-548.

27. Szilvassy SJ. The biology of hematopoietic stem cells. Arch Med Res 2003; 34:446-460

28. Baron F, Storb R, Little MT. Hematopoietic cell transplantation: five decades of progress. Arch Med Res 2003; 34:528-544.

29. Mayani H, Lansdorp PM. Biology of human umbilical cord bloodderived hematopoietic stem/progenitor cells. Stem Cells 1998; 16:153-165.

30. Wognum AW, Eaves AC, Thomas TE. Identification and isolation of hematopoietic stem cells. Arch Med Res 2003; 34:461-475.

31. Cohen Y, Nagler A. Cord blood biology and transplantation. IMAJ 2004; 6:39-46.

32. Mayani H, Alvarado-Moreno JA, Flores-GuzmanP. Biology of human hematopoietic stem and progenitor cells present in circulation. Arch Med Res 2003; 34:476-488.

33. Summer R, Kotton DN, Liang S, Fitzsimmons K, Sun X, Fine A. Embryonic lung side population cells are hematopoietic and vascular precursors. Am J Respir Cell Mol Biol 2005; (en prensa).

34. Hwang WS, Ryu YJ, Park JH, Park ES, Lee EG, Koo JM, et al. Evidence of a pluripotent human embryonic stem cell line derived from a cloned blastocyst. Science 2004; 303:1669-1674.

35. Cowan CA, Klimanskaya I, McMahon J, Atienza J, Witmyer J, Zucker JP, et al. Derivation of embryonic stem-cell lines from human blastocysts. N Engl J Med 2004; 350:1353-1356.

36. Phimister EG, Drazen JM. Two fillips for human embryonic stem cells. N Engl J Med 2004; 350:1351-1352.

37. Tuch BE, Scott H, Armati PJ, Tabiin MT, Wang LP. Use of human fetal tissue for biomedical research in Australia, 1994-2002. Med J Aust 2003; 179:547-550. 
38. Landry DW, Zucker HA. Embryonic death and the creation of human embryonic stem cells. J Clin Invest 2004; 114:1184-1186.

39. Sandel MJ. Embryo ethics - The moral logic of stem-cell research. N Engl J Med 2004; 351:207-209.

40. McHugh PR. Zygote and "clonote" - The ethical use of embryonic stem cells. N Engl J Med 2004; 351:209-211.

41. Kiessling AA. Eggs alone. Human parthenotes: an ethical source of stem cells for therapies? Nature 2005; 434:145.

42. Weimann JM, Charlton CA, Brazelton TR, Hackman RC, Blau HM. Contribution of transplanted bone marrow cells to Purkinje neurons in human adult brains. Proc Natl Acad Sci USA 2003; 100:20882093.

43. Quaini F, Urbanek K, Beltrami AP, Finato N, Beltami CA, NadalGinard B, et al. Chimerism of the transplanted heart. N Engl J Med 2002; 346:5-15

44. Gluckman E, Rocha V, Chastang C, Eurocord-Cord Blood Transplant Group. Cord blood hamtopoietic stem cells biology and transplantation. Hematology 1998; 1:1-14.

45. Sirchia G, Rebulla P. Placental/umbilical cord blood transplantation. Haematologica 1999; 84:738-747.

46. Lewis ID. Clinical and experimental uses of umbilical cord blood. Int Med J 2002; 32:601-609.

47. Rocha V, Sanz G, Gluckman E, Eurocord and European blood and marrow transplant group. Umbilical cord blood transplantation. Curr Opin Hematol 2004; 11:375-385.

48. Gluckman E. Ex vivo expansion of cord blood cells. Exp Hematol 2004; 32:410-412.

49. Wang HS, Hung SC, Peng ST, Huang CC, Wei HM, Guo YJ, et al. Mesenchymal stem cell in the Wharton's jelly of the human umbilical cord. Stem Cells 2004; 22:1330-1337.

50. Arai S, Klingemann HG. Hematopoietic stem cell transplantation: bone marrow vs. mobilized peripheral blood. Arch Med Res 2003; 34:545-553.

51. Daley GQ, Goodell MA, Snyder EY. Realistic prospect for stem cell therapeutics. Hematology 2003; 1:398-418.

52. Stocum DL. Stem cells in CNS and cardiac regeneration. Adv Biochem Eng Biotechnol 2005; 93:135-159.

53. Gerritsen EJA, Vossen JM, Fasth A. Friedrich W, Morgan G, Porras O. Bone marrow transplantation for autosomal recessive osteopetrosis. A report from the Working Party on Inborn Errors of the European Bone Marrow Transplantation Group. J Pediatr 1994; 125:896-902.

54. Porras O. Trasplante de Médula Osea.. Rev Méd Hosp Nal Niños Costa Rica 1993; 26-28(NE):55-76.

55. Weissman IL. Translating stem and progenitor cell biology to the clinic: barriers and opportunities. Science 2000; 287:1442-1446.

56. Chao NJ, Emerson SG, Weinberg KI. Stem cell transplantation (cord blood transplants). Hematology 2004; 1:354-371.

57. Benito AI, Diaz MA, González-Vicent M, Sevilla J, Madero L. Hematopoietic stem cell transplantation using umbilical cord blood progenitors: review of current clinical results. Bone Marrow Transp 2004; 33:675-690.

58. Barker JN, Wagner JE. Umbilical-cord blood transplantation for the treatment of cancer. Nature 2003; 3:526-532.

59. Burgio GR, Gluckman E, Locatelli F. Ethical reappraisal of 15 years of cord-blood transplantation. Lancet 2003; 361:250-252.

60. Davey S, Armitage S, Rocha V, Garnier F, Brown J, Brown CJ, et al. The London Cord Blood Bank: analysis of banking and transplantation outcome. Br J Haematol 2004; 125:358-365.

61. Gluckman E, Eurocord Netcord Organization. Ethical and legal aspects of placental/cord blood banking and transplant. Hematol J 2000; 1:67-69.

62. Ferrari G, Cusella-De Angelis G, Coletta M, Paolucci E, Stornaiuolo A, Cossu G, et al. Muscle regeneration by bone marrow-derived myo- genic progenitors. Science 1998; 279:1528-1530.

63. Ferrari G, Mavilio F. Myogenic stem cells from the bone marrow: a therapeutic alternative for muscular distrophy? Neuromuscul Disord 2002; 12 (S1):7-10.

64. Brazelton TR, Rossi FM, Keshet GI, Blau HM. From marrow to brain: expression of neuronal phenotypes in adult mice. Science 2000; 290:1775-1779.

65. Petersen BE, Bowen WC, Patrene KD, Mars WM, Sullivan AK, Murase N, et al. Bone marrow as a potential source of hepatic oval cells. Science 1999; 284:1168-1170.

66. Theise ND, Badve S, Saxena R, Henegariu O, Sell S, Crawford JM, et al. Derivation of hepatocytes from bone marrow cells in mice after irradiation-induced myeloablation. Hepatology 2000; 31:235-240.

67. Lumelsky N, Blondel O, Laeng P, Velasco I, Ravin R, McKay R. Differentiation of embryonic stem cells to insulin-secreting structures similar to pancreatic islets. Science 2001; 292:1389-1394.

68. Smits AM, van Vliet P, Hassink RJ, Goumans MJ, Doevendans PA. The role of stem cells in cardiac regeneration. J Cell Mol Med 2005; 9:25-36.

69. Yoon YS, Lee N, Scadova H. Myocardial regeneration with bonemarrow-derived stem cells. Biol Cell 2005; 97:253-263.

70. Kumar D, Kamp TJ, Lewinter MM. Embryonic stem cells: differentiation into cardiomyocytes and potential for heart repair and regeneration. Coron Artery Dis 2005; 16:111-116.

71. Jain M, Pfister O, Hajjar RJ, Liao R. Mesenchymal stem cells in the infarcted heart. Coron Artery Dis 2005; 16:93-97.

72. Pandur P. What does it take to make a heart? Biol Cell 2005; 97:197210.

73. Wollert KC, Drexler H. Clinical applications of stem cells for the heart. Circ Res 2005; 96:151-163.

74. Menasche P. Skeletal myoblast for cell therapy. Coron Artery Dis 2005; 16:105-110.

75. Kh Haider H, Ashraf M. Bone marrow stem cells in the infarcted heart. Coron Artery Dis 2005; 16:99-103. 